\title{
Olanzapine-induced Concurrent Tardive Dystonia and Tardive Dyskinesia in Schizophrenia with Intellectual Disability: A Case Report
}

\author{
Young Min Choe ${ }^{1,2}$, So Yeon Kim², Ihn-Geun Choi ${ }^{2,3}$, Guk-Hee Suh ${ }^{1,2}$, Dong Young Lee ${ }^{4,5}$, Boung Chul Lee ${ }^{2,6}$, \\ Jee Wook Kim ${ }^{1,2}$ \\ ${ }^{1}$ Department of Neuropsychiatry, Hallym University Dongtan Sacred Heart Hospital, Hwaseong, ${ }^{2}$ Department of Psychiatry, Hallym University \\ College of Medicine, Chuncheon, ${ }^{3}$ Department of Neuropsychiatry, Hallym University Kangnam Sacred Heart Hospital, Seoul, ${ }^{4}$ Department \\ of Neuropsychiatry, Seoul National University Hospital, ${ }^{5}$ Department of Psychiatry, Seoul National University College of Medicine, ${ }^{6}$ Department \\ of Neuropsychiatry, Hallym University Hangang Sacred Heart Hospital, Seoul, Korea
}

Tardive dystonia and tardive dyskinesia (TDs) are rare extrapyramidal side effects that develop after long-term use of antipsychotics, but they are different syndromes and rarely occur at the same time. Olanzapine is an atypical antipsychotic drug associated with a low risk of extrapyramidal side effects in schizophrenia, but its associations with tardive movements are not clear. We present a case of a 19-year-old Asian female patient with schizophrenia and intellectual disabilities who developed concurrent TDs after long-term use of olanzapine. At her 10-month follow-up examination, her concurrent TDs had been treated successfully with clozapine. This case demonstrates that although the use of olanzapine to treat psychosis and behavioral disturbances is increasing due to its high efficacy and low rate of extrapyramidal side effects, concurrent TDs should be carefully assessed after long-term use of this antipsychotic, especially in patients with schizophrenia and intellectual disabilities. Clozapine, by preventing or reversing the debilitating consequences of concurrent TDs, may be an effective treatment for these patients.

KEY WORDS: Olanzapine; Tardive dystonia; Tardive dyskinesia; Schizophrenia; Intellectual disability.

\section{INTRODUCTION}

Tardive dystonia is a syndrome characterized by sustained muscle contractions that frequently cause twisting and repetitive movements or abnormal postures $[1,2]$. It differs from tardive dyskinesia, the features of which include involuntary, irregular, stereotyped and choreiform or repetitive abnormal movements of the limbs, body and fingers $[1,3]$. Both tardive movement disorders are rare extrapyramidal side effects that begin after the long-term use of antipsychotics $[1,2,4]$; however, they are different disorders and rarely occur at the same time [5-7].

Received: March 27, 2019/ Revised: July 25, 2019

Accepted: September 26, 2019

Address for correspondence: Jee Wook Kim

Department of Neuropsychiatry, Hallym University Dongtan

Sacred Heart Hospital, 7 Keunjaebong-gil, Hwaseong 18450, Korea

E-mail: kimakins@hanmail.net

ORCID: https://orcid.org/0000-0002-9570-4216
Olanzapine is an atypical antipsychotic associated with a low risk of extrapyramidal side effects in schizophrenia (SPR) [8]. In addition, some studies have shown that it improves the symptoms of tardive dystonia and tardive dyskinesia (TDs) [9-12], whereas others have found that olanzapine actually causes tardive dystonia or tardive dyskinesia [13-15]. There are no reported cases of olanzapine-induced concurrent TDs. In SPR patients with intellectual disabilities (IDs), the risk of TDs may be higher because SPR patients often require long-term treatment with antipsychotics, and IDs themselves may be a risk factor for TDs $[2,16]$. However, the effect of olanzapine on the development of these syndromes in SPR patients with IDs is unknown. Here, we report the case of a young female SPR patient with IDs who developed concurrent TDs while on long-term olanzapine. Treatment with clozapine resulted in the resolution of her concurrent TDs.

(c) This is an Open-Access article distributed under the terms of the Creative Commons Attribution Non-Commercial License (http://creativecommons.org/licenses/by-nc/4.0) which permits unrestricted non-commercial use, distribution, and reproduction in any medium, provided the original work is properly cited. 


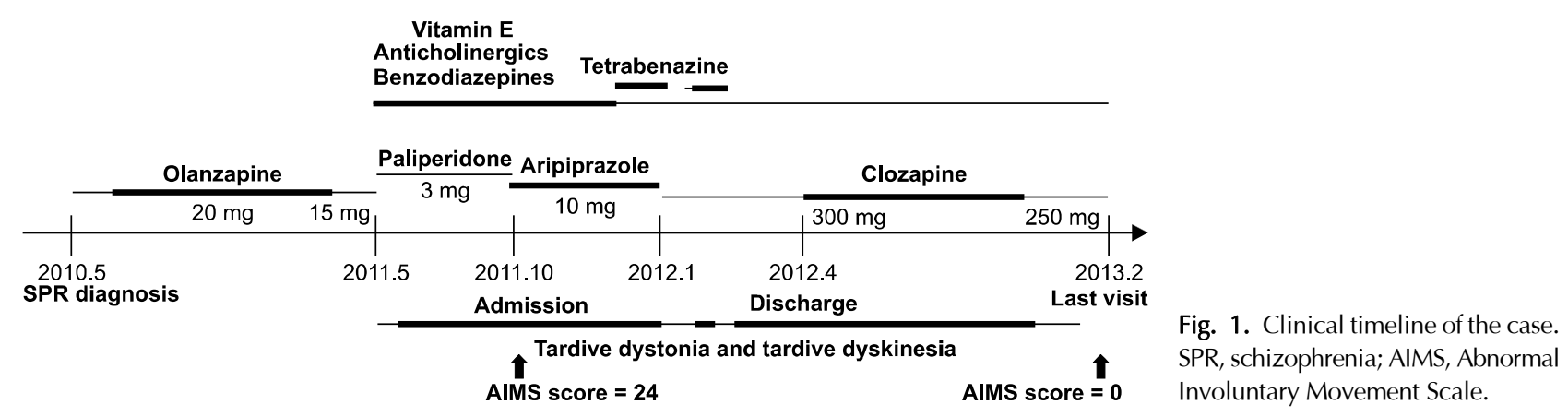

\section{CASE}

The patient was a 19-year-old Korean woman with moderate IDs. An intelligence test revealed a full-scale intelligence quotient of 39 on the Wechsler Adult Intelligence Scale. As shown in Figure 1, she was diagnosed with SPR and treated with $20 \mathrm{mg} /$ day olanzapine, which led to complete remission of her psychotic symptoms of delusion and auditory hallucinations. One year later, during which time she continued olanzapine treatment, her neck started turning intermittently and involuntarily to the left. This severe, frequent, and spasmodic torticollis (also called cervical dystonia) caused her marked distress. In addition, she experienced aberrant eye blinks, abnormal tongue movements, and involuntary and irregular stereotyped choreiform or repetitive abnormal movements of the neck, trunk, face, and upper extremities. Her total Abnormal Involuntary Movement Scale (AIMS) score was 24. A neurologic exam with electroencephalography and blood tests, including plasma $\mathrm{Cu}^{2+}$ levels, was performed to rule out Wilson's disease and other metabolic diseases. The results were negative. She had no history of alcohol or substance abuse and no family history of psychiatric or neurologic disorders. After olanzapine therapy was discontinued, we started $3 \mathrm{mg}$ paliperidone and later switched to $10 \mathrm{mg}$ aripiprazole to prevent worsening of the psychosis. Treatment with $12 \mathrm{mg}$ trihexyphenidyl, $2 \mathrm{mg}$ benztropine, $3 \mathrm{mg}$ lorazepam, $3 \mathrm{mg}$ clonazepam, and $800 \mathrm{IU}$ vitamin $\mathrm{E}$ in combination with $3 \mathrm{mg}$ paliperidone or $10 \mathrm{mg}$ aripiprazole was ineffective, and her concurrent TDs persisted without improvement. During tapering of her anticholinergics or benzodiazepines, $75 \mathrm{mg}$ tetrabenazine was added to her drug regimen, which resulted in a dramatic but still partial improvement of her concurrent TDs. However, she experienced prominent psychomotor retardation and a dull sensation. Therefore, clozapine treatment was initiated and the dose titrated to 300 $\mathrm{mg} /$ day, and her other medications were discontinued. At her 10-month follow-up examination, her concurrent TDs had completely disappeared, and she felt no distress. Eventually, her condition was successfully treated with $250 \mathrm{mg}$ clozapine, $1 \mathrm{mg}$ benztropine, and $1 \mathrm{mg}$ clonazepam. Her final AIMS score was 0.

\section{DISCUSSION}

Our young female SPR patient with IDs developed concurrent TDs while on long-term olanzapine. Her concurrent TDs fully resolved after she started clozapine.

This case differs from previous reports of antipsychotic-induced TDs. First, it suggests that a diagnosis of SPR in patients with pre-existing IDs increases the risk of concurrent TDs while on long-term antipsychotic treatment. IDs are common in individuals with SPR [17], and they increase the risk of TDs $[16,18]$. Therefore, our patient, with both SPR and IDs, was at high risk of tardive movements. Second, the patients suffered from concurrent TDs. According to one study, the relationship between the two extrapyramidal syndromes suggests that having tardive dyskinesia increases the probability of developing tardive dystonia [19]. However, whether tardive dyskinesia is specifically related to tardive dystonia is unknown. Since tardive dyskinesia causes intense suffering in affected patients, the strong possibility of concurrence suggests that these patients should also be carefully monitored for tardive dystonia.

Both the baseline diagnosis and the medication used for its treatment may contribute to tardive movements. Olanzapine is an atypical antipsychotic associated with a low risk of extrapyramidal side effects, including tardive movements, in SPR, but the exact relationship between olanzapine and tardive movements is unknown. Regard- 
ing the pathophysiology of olanzapine-induced concurrent TDs, olanzapine at therapeutic doses is associated with a higher $\mathrm{D}_{2}$-receptor occupancy compared with clozapine which is not associated with tardive movements [20]. Thus, olanzapine may have been responsible for the development of concurrent TDs in our patient.

Previous studies have suggested that aripiprazole is an effective treatment for tardive dyskinesia [21-23]; however, this drug did not lead to a significant improvement in our patient. Aripiprazole has a high affinity for $\mathrm{D}_{2}$-receptors and a weak affinity for $\mathrm{D}_{1}$-receptors, which could lead to an imbalance between $D_{1}$ - and $D_{2}$-mediated striatal outputs $[1,23,24]$. While chronic neuroleptic use results in high $\mathrm{D}_{2}$-receptor blockade, a lower occupancy rate of $D_{1}$-receptors may lead to sensitization of $D_{1}$-mediated striatal output and, in turn, to abnormal movements [25].

In our patient, while the concurrent TDs improved in response to anticholinergics, benzodiazepines, vitamin $\mathrm{E}$, and tetrabenazine, there was a more substantial improvement with clozapine. Clozapine is associated with absent or fewer extrapyramidal symptoms and tardive movements than are other antipsychotics [26]. Clozapine also has a lower $\mathrm{D}_{2}$-receptor occupancy [27] and higher $\mathrm{D}_{1}$ receptor occupancy. This profile may have contributed to the restoration of the $\mathrm{D}_{1}$ - and $\mathrm{D}_{2}$-receptor balance [25].

In conclusion, olanzapine is increasingly being used to treat psychosis and behavioral disturbance because of its high efficacy and low risk of extrapyramidal side effects. However, this case report highlights the need for careful assessment of concurrent TDs in patients with long-term use of olanzapine, especially patients with SPR and IDs. Clozapine may be an effective approach for patients with concurrent TDs, either in preventing or reversing the debilitating consequences of this condition.

\section{Conflicts of Interest}

No potential conflict of interest relevant to this article was reported.

\section{Author Contributions}

Conceptualization: Young Min Choe, So Yeon Kim, Ihn-Geun Choi, Guk-Hee Suh, Dong Young Lee, Jee Wook Kim. Data acquisition: So Yeon Kim, Ihn-Geun Choi, Guk-Hee Suh, Boung Chul Lee, Jee Wook Kim. Supervision: Jee Wook Kim. Writing-original draft: Young Min Choe, So Yeon Kim, Jee Wook Kim. Writing - review \& editing: Young Min Choe, So Yeon Kim, Ihn-Geun Choi, Guk-Hee Suh, Dong Young Lee, Boung Chul Lee, Jee Wook Kim.

\section{ORCID}

Young Min Choe https://orcid.org/0000-0002-9263-876X

So Yeon Kim https://orcid.org/0000-0002-8123-4030 Ihn-Geun Choi https://orcid.org/0000-0002-9183-2827 Guk-Hee Suh https://orcid.org/0000-0003-4303-0368 Dong Young Lee https://orcid.org/0000-0001-8976-8320 Boung Chul Lee https://orcid.org/0000-0002-0968-087X Jee Wook Kim https://orcid.org/0000-0002-9570-4216

\section{REFERENCES}

1. Kim S, Lee SY, Kim M, Lee KU. Tardive dystonia related with aripiprazole. Psychiatry Investig 2017;14:380-382.

2. Friedman JH, Kucharski LT, Wagner RL. Tardive dystonia in a psychiatric hospital. J Neurol Neurosurg Psychiatry 1987;50: 801-803.

3. Ricciardi L, Pringsheim T, Barnes TRE, Martino D, Gardner D, Remington G, et al. Treatment recommendations for tardive dyskinesia. Can J Psychiatry 2019;64:388-399.

4. van Harten PN, Kahn RS. Tardive dystonia. Schizophr Bull 1999;25:741-748.

5. Yassa $\mathrm{R}, \mathrm{Nair} \mathrm{V}$, Iskandar $\mathrm{H}$. A comparison of severe tardive dystonia and severe tardive dyskinesia. Acta Psychiatr Scand 1989;80:155-159.

6. Sachdev P. Risk factors for tardive dystonia: a case-control comparison with tardive dyskinesia. Acta Psychiatr Scand 1993;88:98-103.

7. Pitzer M, Engelmann G, Stammschulte T. [Tardive movement disorders with antipsychotics - a case of aripirazole-induced tardive dystonia and review of the literature]. Z Kinder Jugendpsychiatr Psychother 2017;45:325-334. German.

8. Tollefson GD, Beasley CM Jr, Tamura RN, Tran PV, Potvin JH. Blind, controlled, long-term study of the comparative incidence of treatment-emergent tardive dyskinesia with olanzapine or haloperidol. Am J Psychiatry 1997; 154:1248-1254.

9. Lin JJ, Chang DC. Improvement of generalised dystonia by olanzapine treatment. J Clin Neurosci 2004;11:84-86.

10. Jaffe ME, Simpson GM. Reduction of tardive dystonia with olanzapine. Am J Psychiatry 1999;156:2016.

11. Lucetti C, Bellini G, Nuti A, Bernardini S, Dell'Agnello G, Piccinni A, et al. Treatment of patients with tardive dystonia with olanzapine. Clin Neuropharmacol 2002;25:71-74.

12. Truöl S, Von Hippel C, Raape J, König F. [Improvement of tardive dyskinesia after treatment with olanzapine]. Psychiatr Prax 2002;29:315-317. German.

13. Bhanji NH, Margolese HC. Tardive dyskinesia associated with olanzapine in a neuroleptic-naive patient with schizophrenia. Can J Psychiatry 2004:49:343. 
14. Szafrański T. [Tardive dyskinesia in patients with schizophrenia treated with olanzapine - results from a 20-month, prospective, open study under naturalistic conditions]. Psychiatr Pol 2014;48:1155-1165. Polish.

15. Sangroula D, Virk I, Mohammad W, Kahn DA. Clozapine treatment of olanzapine-induced tardive dyskinesia: a case report. J Psychiatr Pract 2017;23:53-59.

16. Cohen S, Khan A, Zheng Y, Chiles J. Tardive dyskinesia in the mentally retarded: comparison of prevalence, risk factors and topography with a schizophrenic population. Acta Psychiatr Scand 1991;83:234-237.

17. Reid AH. Schizophrenia in mental retardation: clinical features. Res Dev Disabil 1989;10:241-249.

18. Newell KM, Ko YG, Sprague RL, Mahorney SL, Bodfish JW. Onset of dyskinesia and changes in postural task performance during the course of neuroleptic withdrawal. Am J Ment Retard 2002;107:270-277.

19. van Harten PN, Hoek HW, Matroos GE, Koeter M, Kahn RS. The inter-relationships of tardive dyskinesia, parkinsonism, akathisia and tardive dystonia: the Curaçao Extrapyramidal Syndromes Study II. Schizophr Res 1997;26:235-242.

20. Kapur S, Zipursky RB, Remington G, Jones C, DaSilva J, Wilson AA, et al. 5-HT2 and D2 receptor occupancy of olanzapine in schizophrenia: a PET investigation. AmJ Psychiatry
1998;155:921-928.

21. Brown HE, Flaherty AW, Goff DC, Freudenreich O. A case of dramatic improvement of severe tardive dyskinesia after switch to aripiprazole. Prim Care Companion CNS Disord 2011;13:PCC.11101188.

22. Chan $\mathrm{CH}$, Chan HY, Chen YC. Switching antipsychotic treatment to aripiprazole in psychotic patients with neuroleptic-induced tardive dyskinesia: a 24-week follow-up study. Int Clin Psychopharmacol 2018;33:155-162.

23. Kang NR, Kim MD. Tardive dyskinesia: treatment with aripiprazole. Clin Psychopharmacol Neurosci 2011;9:1-8.

24. Lim HK, Pae CU, Lee C, Lee CU. Tardive dystonic symptoms associated with aripiprazole treatment. Prog Neuropsychopharmacol Biol Psychiatry 2008;32:589-590.

25. Trugman JM, Leadbetter R, Zalis ME, Burgdorf RO, Wooten GF. Treatment of severe axial tardive dystonia with clozapine: case report and hypothesis. Mov Disord 994;9:441-446.

26. Simpson GM. The treatment of tardive dyskinesia and tardive dystonia. J Clin Psychiatry 2000;61 Suppl 4:39-44.

27. Lako IM, van den Heuvel ER, Knegtering H, Bruggeman R, Taxis K. Estimating dopamine $D_{2}$ receptor occupancy for doses of 8 antipsychotics: a meta-analysis. J Clin Psychopharmacol 2013;33:675-681. 